\title{
Incidental finding of pulmonary artery aneurysm revealing a congenital heart defect
}

\author{
Kelly Alice Drivdahl Dougherty, ${ }_{1}{ }^{1}$ Mahmoud Elkaissi, ${ }^{2}$ Hani Sabbour, ${ }_{1}^{3}$ Samar Farha ${ }^{4}$
}

\begin{abstract}
${ }^{1}$ New York University School of Medicine, New York City, New York, USA

${ }^{2}$ Imaging Institute, Cleveland Clinic Abu Dhabi, Abu Dhabi, United Arab Emirates

${ }^{3}$ Heart and Vascular Institute, Cleveland Clinic Abu Dhabi, Abu Dhabi, United Arab Emirates ${ }^{4}$ Respiratory and Critical Care Institute, Cleveland Clinic Abu Dhabi, Abu Dhabi, United Arab Emirates
\end{abstract}

\section{Correspondence to} Kelly Alice Drivdahl Dougherty, kad418@nyu.edu

Accepted 3 June 2019

\section{DESCRIPTION}

A middle-aged former smoker with a medical history of chronic obstructive pulmonary disease (COPD) and idiopathic pulmonary arterial hypertension (IPAH) was transferred to our facility for management of a pulmonary artery aneurysm (PAA) found on CT scan of the chest. The patient was diagnosed with IPAH 13 years prior to current presentation and had been on dual pulmonary hypertension therapy (macitentan and sildenafil) with improvement in 6 min walking distance and functional class. At the outside facility, the patient was admitted for a respiratory tract infection and treated with antibiotics. A CT scan of the chest revealed pulmonary consolidation and PAA (figure 1).

On admission to our centre, the patient's blood pressure was $156 / 83 \mathrm{~mm} \mathrm{Hg}$, heart rate was 105 beats/min and oxygen saturation was $95 \%$ on $3 \mathrm{~L} /$ min oxygen by nasal cannula. Physical examination revealed a loud S2, a holosystolic murmur at the left sternal border, diffuse wheezing and lower extremity cyanosis and mild clubbing not noted in the upper extremities. Transthoracic echocardiogram revealed normal left ventricular function, moderately dilated and severely hypertrophic right ventricle with mildly decreased function and an estimated right ventricular systolic pressure of $97 \mathrm{~mm} \mathrm{Hg}$. A right heart catheterisation showed mean pulmonary artery

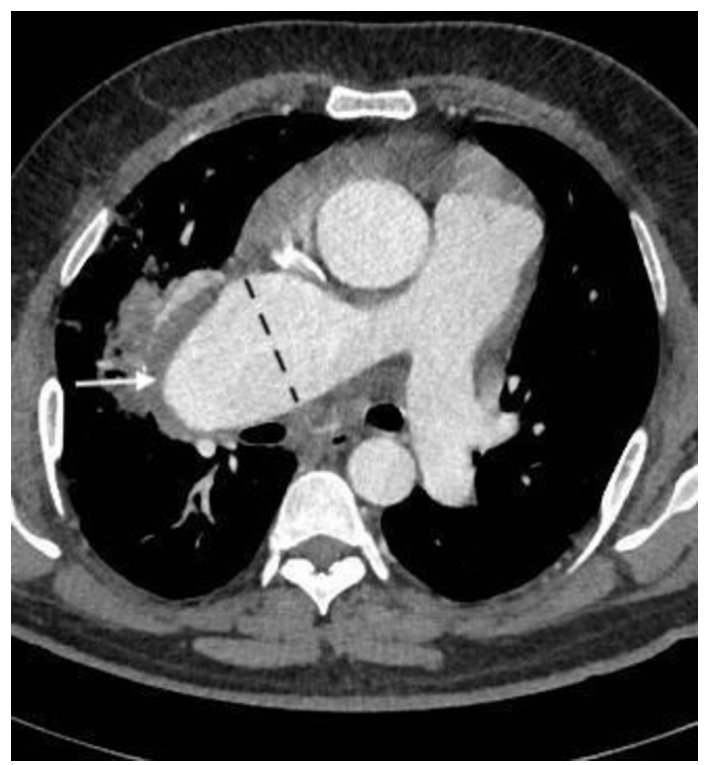

Figure 1 CT scan showing evidence of right heart strain with a right pulmonary artery aneurysm measuring $54.1 \mathrm{~mm}$ with hypodensity suggesting intramural thrombus. Cross-section highlighting aneurysm and arrow pointing at intramural thrombus.

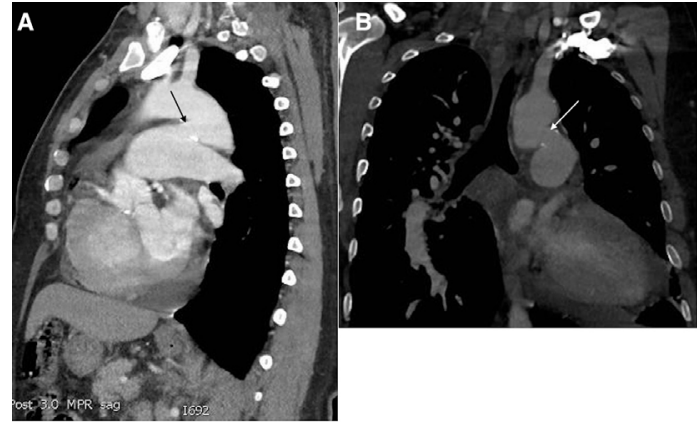

Figure 2 CT scan of newly identified PDA. (A) Wide PDA connecting the inferior surface of the descending aorta to main pulmonary trunk. PDA measures $18.4 \mathrm{~mm}$. (B) PDA in the coronal plane. Arrows point at PDA. PDA, patent ductus arteriosus.

pressure (PAP) of $98 \mathrm{~mm} \mathrm{Hg}$, cardiac output $9.27 \mathrm{~L} /$ min and pulmonary vascular resistance (PVR) of 8.6 wood units. Six-minute walk distance was $384 \mathrm{~m}$ with desaturation to $78 \%$ on room air. Pulmonary function testing showed forced expiratory volume in 1 second $\left(\mathrm{FEV}_{1}\right)$ of $23 \%$ predicted, forced vital capacity (FVC) of $48 \%$ predicted, $\mathrm{FEV}_{1} / \mathrm{FVC}$ of $37 \%$ with a positive bronchodilator response. Haemoglobin was $159 \mathrm{~g} / \mathrm{L}$. CT scan of the chest revealed a right PAA $54.1 \mathrm{~mm}$ in anteroposterior diameter compressing the pulmonary vein and right bronchus, a right upper lobe consolidation and a patent ductus arteriosus (PDA) measuring $18.4 \mathrm{~mm}$ (figures 1 and 2). At the time of his presentation to our facility, outside records were not available.

Based on the CT scan findings, PAH classification was changed to $\mathrm{PAH}$ associated with congenital heart disease (PAH-CHD). In view of the elevated PAP and PVR, surgical intervention was not offered. Our decision was to optimise medical management for PAH and COPD and have close follow-up.

Learning points

- The disease course of idiopathic pulmonary hypertension is progressive. Patients that remain stable for many years should be reevaluated for underlying causes, in particular, associated congenital heart defects.

- Half of all pulmonary artery aneurysms are associated with congenital heart disease. Identification of an aneurysm should prompt further imaging, especially in the presence of other signs of congenital heart disease. 
PAH-CHD comprises $21 \%$ of WHO category 1 PAH. ${ }^{1}$ A PDA shunt lesion is identified in $1 \%$ of adults with PAH-CHD. ${ }^{2}$ As evidenced in this case, PDAs are easily missed on echocardiography, resulting in patients being misdiagnosed as IPAH. Additionally, congenital heart diseases have been recognised as the major reason for PAA formation with more than $50 \%$ of all cases associated with congenital heart defects. The most commonly associated lesions are PDAs, ventricular septal defects and atrial septal defects. ${ }^{3}$

In conclusion, our patient's disease stability over 13 years and the findings of PAA were indicative of an associated congenital heart defect. This case demonstrates the challenges and nuance of working up pulmonary hypertension and the importance of thorough diagnostic procedures and imaging.

Contributors KADD was responsible for the writing of the case report as well as the compilation, editing and preparation for submission. SF was responsible for planning, writing, editing and interface with the patient. ME assisted with selection, annotation and captioning of the images. HS planned, edited the text and provided cardiology perspective.

Funding The authors have not declared a specific grant for this research from any funding agency in the public, commercial or not-for-profit sectors.

Competing interests None declared.

Patient consent for publication Obtained.

Provenance and peer review Not commissioned; externally peer reviewed.

\section{REFERENCES}

1 Gall H, Felix JF, Schneck FK, et al. The Giessen Pulmonary Hypertension Registry: Survival in pulmonary hypertension subgroups. J Heart Lung Transplant 2017;36:957-67.

2 Lowe BS, Therrien J, Ionescu-Ittu R, et al. Diagnosis of pulmonary hypertension in the congenital heart disease adult population impact on outcomes. J Am Coll Cardiol 2011:58:538-46.

3 Kreibich M, Siepe M, Kroll J, et al. Aneurysms of the pulmonary artery. Circulation 2015;131:310-6.

Copyright 2019 BMJ Publishing Group. All rights reserved. For permission to reuse any of this content visit

https://www.bmj.com/company/products-services/rights-and-licensing/permissions/

BMJ Case Report Fellows may re-use this article for personal use and teaching without any further permission.

Become a Fellow of BMJ Case Reports today and you can:

- Submit as many cases as you like

- Enjoy fast sympathetic peer review and rapid publication of accepted articles

- Access all the published articles

Re-use any of the published material for personal use and teaching without further permission

Customer Service

If you have any further queries about your subscription, please contact our customer services team on +44 (0) 2071111105 or via email at support@bmj.com.

Visit casereports.bmj.com for more articles like this and to become a Fellow 